\title{
Convalescent Plasma Therapy for pregnant patients with COVID-19: Case Series
}

\author{
Mariam Ayed ${ }^{* 1}$, Farah Alshammari ${ }^{2}$, Amal Ayed ${ }^{3}$, Ibrahim Gadalla ${ }^{4}$, Fawaz Aldoohan ${ }^{2}$, \\ Sondos Alsharidah ${ }^{5}$
}

${ }^{1}$ Neonatal Department, Farwaniya Hospital, Kuwait

${ }^{2}$ Department of Internal Medicine, New Jahra Hospital, Kuwait

${ }^{3}$ Obstetric and Gynecology Department, Farwaniya Hospital, Kuwait

${ }^{4}$ Obstetric and Gynecology Department, New Jahra Hospital, Kuwait

${ }^{5}$ Sondos Alsharidah, Stem Cell Transplant Unit, Pediatric Hematology Oncology Department National Bank Kuwait Specilized Children Hospital, Kuwait

*Corresponding author: Mariam Ayed, Neonatal Department, Farwaniya Hospital, Subah an Nasser, Kuwait City, Postal code-81400, Kuwait, Tel: 965-98880553,Email: Mariam.ayed@ hsc.edu.kw

Received 12 September 2021;

Accepted 11 November 2021;

Published 14 November 2021

\begin{abstract}
Aim: The objective of this study is to report the effect of COVID-19 convalescent plasma (CCP) therapy in pregnant women with moderate or severe COVID-19 infection. Methods: This study is a case series of 9 pregnant women with moderate or severe COVID-19 infection. All the patients $(\mathrm{N}=9)$ received two doses $(400 \mathrm{~mL})$ of $\mathrm{ABO}$ compatible CCP. The median gestational age at the time of confirmed COVID-19 diagnosis was 31 weeks (range: 16-39 weeks). Results: No adverse events with CCP were reported. On day 3 post-CCP administration, there was a significant improvement in oxygen saturation $(\mathrm{p}=0.032)$, decrease in the respiratory rate from baseline $(\mathrm{p}=0.041)$, and improvement in the lymphocyte counts $(\mathrm{p}=0.043)$. None of the patients required invasive ventilatory support or extracorporeal membrane oxygenation and all were discharged home (median time from CCP administration to discharge was 6 days). All the patients gave birth to healthy newborns. The newborns had negative SARS-CoV-2 PCR on days 2 and 5 of ages. Conclusion: Our case series demonstrated CCP therapy to be safe with improved clinical outcomes during moderate and severe COVID-19 infection in pregnancy. However, extensive studies are still needed to recommend the routine use of CCP in the pregnant population with COVID-19 disease.

Trial Registration: Clinicaltrials.gov NCT04474340.
\end{abstract}

Keywords: Convalescent plasma, COVID-19, Case series, Pregnancy, SARS-CoV-2

\section{Introduction}

The World Health Organisation (WHO) has termed the global spread of the viral pandemic in the year 2020-21 as coronavirus disease-2019 (COVID-19) ${ }^{[1]}$. COVID-19 is known to cause by a novel coronavirus and is named the severe acute respiratory syndrome coronavirus-2 (SARS-CoV-2) because of its genetic similarity to the coronavirus (SARS-CoV-1) that lead to the outbreak of the SARS epidemic in 2002-2003 ${ }^{[2]}$. To date, 114,315,846 confirmed cases of COVID-19 and 2,539,427 deaths had occurred globally ${ }^{[3]}$. Approximately 2 billion women of childbearing age ${ }^{[4]}$ and other pregnant women ${ }^{[5,6]}$ worldwide are estimated to be at a higher risk of catching COVID-19 infection. Recently, a study by the Centers for Disease Control and Prevention (CDC) reported $2 \%$ of cases in pregnant women out of a total of 7162 COVID-19 patients in the United States ${ }^{[7]}$. Furthermore, increased maternal age ( $>35$ years) and comorbidities such as hypertension, chronic cardiovascular diseases, diabetes, pulmonary disease, and other malignancies may further increase the complications due to COVID-19 in pregnant women ${ }^{[8]}$.

Pregnant females infected with COVID-19 present with symptoms similar to those in non-pregnant adults with COVID-19. The clinical features include fever, cough, breathlessness, loss of taste and smell, headache, and also pneumonia in a few complicated cases ${ }^{[9,10]}$. Although most of the cases with SARSCoV-2 infection during pregnancy (85\%-90\%) are associated with no or only mild symptoms, $5 \%-10 \%$ of patients may have severe symptoms, enough to authorize hospitalization or oxygen therapy while 1\%-2\% may become critical requiring assisted ventilation or may even die ${ }^{[11]}$. However, till now, no significant data is 
available on fetal infection or intrauterine transmission of COVID19. Nonetheless, COVID-19 during pregnancy is reported to increase the threat of preeclampsia, premature delivery, cesarean section, low weight baby, fetal distress, abortion, neonatal asphyxia, and neonatal death ${ }^{[12,13]}$.

Several therapeutic options, including antiviral drugs such as remdesivir, favipiravir, and other medications as chloroquine, azithromycin, tocilizumab, and bamlanivimab plus etesevimab combination, have been suggested for patients with COVID-19 (Treatment guidelines, NIH). However, due to the lack of clear evidence regarding the efficacy and safety of these treatments, the therapeutic armamentarium for COVID-19 is currently limited. Considering the systemic hyper-inflammatory impact of SARS$\mathrm{CoV}-2$ infection, adjunctive treatments such as the passive immunization with the convalescent plasma obtained from recently cured COVID-19 patients are also being explored for the management of moderate to seriously ill COVID-19 patients ${ }^{[14]}$. In the past, convalescent plasma therapy has already proven safe in fighting against various viral diseases such as poliomyelitis, measles, mumps, Spanish influenza, and SARS ${ }^{[15-17]}$. Additionally, clinical data from a systematic study has found convalescent plasma to be effective in treating COVID-19 patients ${ }^{[18]}$. The Food and Drug Administration (FDA) has authorized the emergency application of COVID-19 convalescent plasma (CCP) treatment for severe COVID-19 patients ${ }^{[19]}$.

At the same time, it is also urgent to establish effective and safe alternatives for treating pregnant women with COVID-19, as are available for the general or non-pregnant population. Given the initial positive clinical outcomes related to safety and efficacy features of CCP in COVID-19 patients, this treatment is gaining interest among the investigators for its considerable use in pregnant women as well. However, the data is still insufficient and mostly includes case reports, case series, or cohort studies [20-23]. Moreover, out of a total of 91 COVID-19 interventional clinical trials on convalescent plasma studies, currently, in progress, 44 $(\sim 48 \%)$ trials have excluded pregnant and breastfeeding women due to safety concerns for the mother and to avoid any potential teratogenic effects ${ }^{[23]}$.

Therefore, we report here the case series of 9 pregnant women with moderate and severe COVID-19 infection who were successfully managed with CCP therapy.

\section{Materials and Methods}

\section{Research Design and Subjects}

This is a case series study on pregnant women with SARS-CoV-2 infection, who were hospitalized to New-Jahra hospital, Kuwait, from 1st September 2020 to 14th November, 2020. The inclusion/exclusion criteria for the selection of patients are provided and have also been described in our earlier published paper ${ }^{[24]}$. The written informed consent was taken from each patient. The Ethics Committee of the Ministry of Health of Kuwait (2020/1417\&1420) approved the present study (and is registered at Clinicaltrials.gov NCT04474340).

\section{Inclusion and exclusion criteria for patients' selection}

\section{Inclusion Criteria}

If the patients had moderate or severe COVID-19 (per WHO classification) at admission, as determined by the physician.

WHO classification ${ }^{[25]}$.
1. Moderate COVID-19: Defined as the presence of clinical signs of pneumonia (fever, cough, dyspnea) and oxygen saturation $(\mathrm{SpO} 2)$ of more than $90 \%$ in room air.

2. Severe COVID-19: Defined as clinical signs of pneumonia plus $\mathrm{SpO} 2$ less than $90 \%$ in room air or admission to intensive care unit (ICU) for respiratory support (i.e., high flow nasal cannula, non-invasive mechanical ventilation, and intubation).

\section{Exclusion Criteria}

1. Contraindication to blood transfusion (volume overload, history of anaphylaxis to blood products)

2. Acute multiple organ failure

3. Hemodynamic instability

4. Severe disseminated intravascular coagulopathy (DIC)

5. Septic shock

6. Expected survival of less than 48 hours

\section{Collection of COVID-19 Convalescent plasma (CCP)}

The inclusion/exclusion criteria for the selection of donor patients for CCP collection have been provided [24] All the donors tested negative for human leukocyte antigen (HLA) antibodies. CCP was only collected from individuals who met all donor eligibility requirements according to the United States Code of Federal Regulations (21 CFR 630.10 and 21 CFR 630.15). All donors had been tested negative respiratory viruses, as well as for hepatitis B virus, hepatitis $\mathrm{C}$ virus, HIV, and syphilis at the time of blood donation. Neutralizing antibodies were not measured. All the enrolled pregnant patients $(\mathrm{N}=9)$ received 2 doses of $\mathrm{ABO}$ compatible CCP (each unit contains $200 \mathrm{~mL}$ ) 12 hours apart as described previously ${ }^{[24]}$.

Inclusion and exclusion criteria for selecting donor patients for collection of $\mathrm{CCP}$

\section{Inclusion Criteria}

1. Convalesced from confirmed COVID-19 disease and

2. Positive against SARS-CoV-2.

3. Asymptomatic for at least 10 days

\section{Exclusion Criteria}

1. Tested positive for only $\operatorname{IgM}$ and negative for $\operatorname{IgG}$ antibodies against SARS-CoV-2

\section{Data Collection}

The following data were collected from 9 eligible pregnant women (who received CCP from the eligible donors, as described above) by reviewing the hospital's electronic medical record. Patients were followed up until hospital discharge or giving birth whichever comes later.

1. Demographic data: Included presenting symptoms, gestational age at the time of confirmation of COVID-19, and co-existing medical conditions.

2. Details on personalized therapies: Antenatal corticosteroids for fetal lung maturation, antibiotics, antivirals, and prophylaxis for thrombosis (such as lowmolecular weight heparin).

3. Clinical and laboratory findings (pre-and post- CCP transfusion in the patients): Respiratory rate, oxygen saturation, lymphocyte count, white blood cell count, levels of C-reactive protein (CRP), D-dimer, and lactate dehydrogenase (LDH). 
4. Neonatal data: Gestational age at the time of delivery, type of delivery method, weight of baby at birth, 5minutes Apgar score, COVID-19 PCR test results (at 48 hours of age), and hospitalization to neonatal intensive care unit (NICU; if yes/no).

\section{Statistical analysis}

Data were analyzed using STATA/IC 14 software (STATA Corp, College Station, Texas). Continuous variables were summarized as median and range, while categorical variables were summarized as numbers and percentages. Clinical characteristics and laboratory values before and after CCP treatment were compared by Wilcoxon signed-rank test. A p value of $<0.05$ was considered statistically significant.

\section{Results}

A total of 9 eligible pregnant women with confirmed COVID-19 who received CCP were enrolled in the study.

\section{Patients' demographic and clinical characteristics}

The median age of the patients was 29 years (range 23-39 years). The median gestational age at the time of confirmation of COVID19 was 31 weeks (range 16-39 weeks). Three patients had severe COVID-19, while 6 had a moderate disease. The most common symptoms at presentation were cough $(n=7)$, fever $(n=5)$, and shortness of breath $(n=4)$. Other symptoms seen were headache $(n=2)$ and diarrhea $(n=1)$. The demographic and clinical features of these patients have been given in Table 1 .

Table 1: Demographic and clinical features of pregnant patients enrolled in the study ( $N=9)$

\begin{tabular}{|l|l|l|l|l|l|l|}
\hline Patient & $\begin{array}{l}\text { Age } \\
\text { (years) }\end{array}$ & Parity & $\begin{array}{l}\text { Gestational age at } \\
\text { diagnosis of COVID-19 }\end{array}$ & $\begin{array}{l}\text { Co-existing chronic } \\
\text { condition }\end{array}$ & Presenting symptoms & $\begin{array}{l}\text { WHO } \\
\text { classification }\end{array}$ \\
\hline 1 & 30 & 2 & 31 weeks & None & Cough, fatigue & Moderate \\
\hline 2 & 29 & 1 & 30 weeks & None & Cough & Moderate \\
\hline 3 & 29 & 0 & 22 weeks & None & Fever, cough, shortness of breath & Moderate \\
\hline 4 & 23 & 0 & 36 weeks & None & Fever, cough, shortness of breath & Severe \\
\hline 5 & 37 & 4 & 16 weeks & None & Cough, shortness of breath, fatigue & Moderate \\
\hline 6 & 29 & 1 & 23 weeks & Bronchial asthma & Headache, fever & Moderate \\
\hline 7 & 36 & 2 & 39 weeks & None & Cough, fever, diarrhoea & Moderate \\
\hline 8 & 39 & 3 & 34 weeks & None & Fever, shortness of breath, headache & Severe \\
\hline 9 & 28 & 2 & 34 weeks & None & Cough, fatigue, sore throat & Severe \\
\hline
\end{tabular}

\section{Patient-specific therapies}

Each patient $(\mathrm{N}=9)$ was given low molecular weight heparin and antibiotics (ceftriaxone and azithromycin) to avoid possible superimposed bacterial infection. The majority of the patients $(\mathrm{n}=7)$ received dexamethasone for fetal lung maturation. None of the patients received antiviral treatment or hydroxychloroquine.

The median days of receiving CCP from the date of diagnosis of COVID-19 were 5 days (range 3-7 days). No adverse events were observed in none of the 9 patients after CCP transfusion

\section{Study Outcomes}

(I) Maternal outcomes

Clinical course of the patients

The trajectory of oxygen and ventilator support overtime for all 9 patients has been shown in Fig. 1.

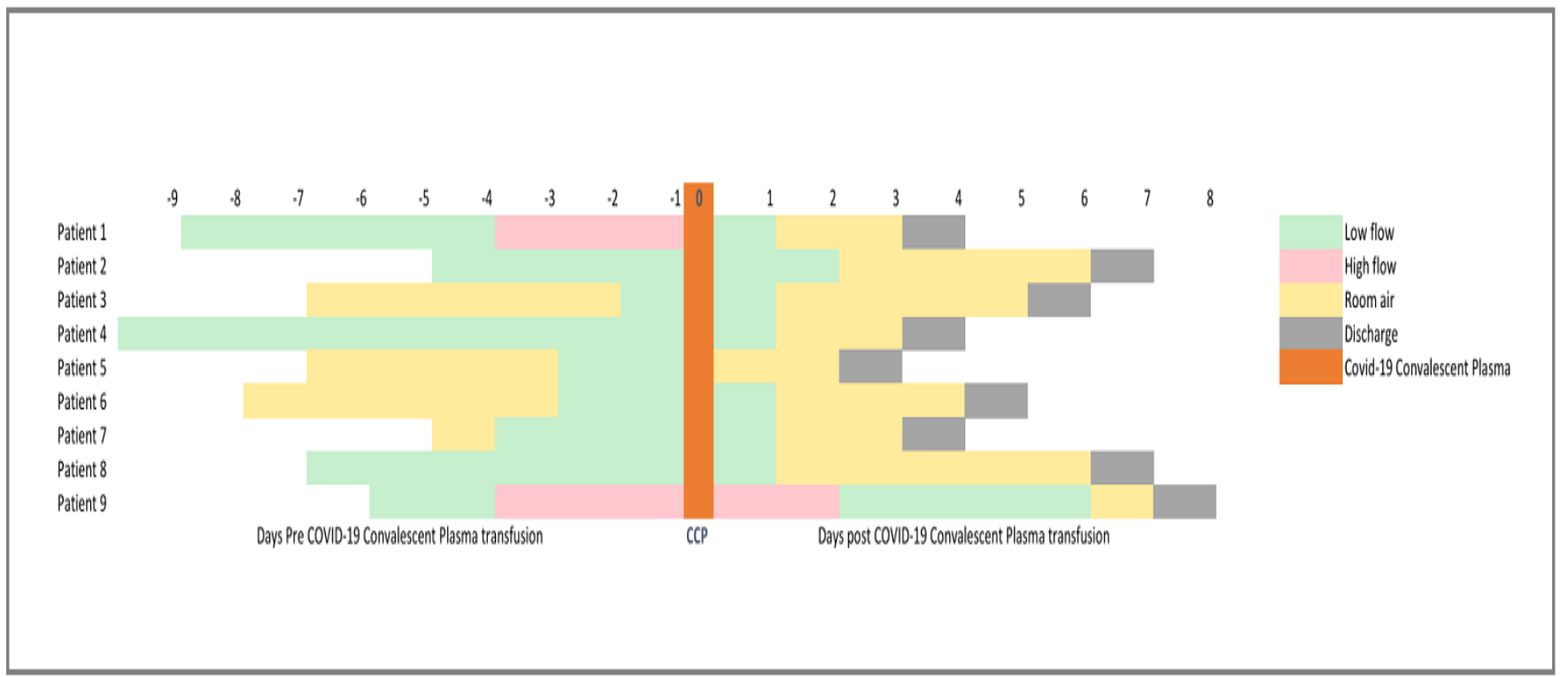

Fig. 1: Clinical course of the patients $(N=9)$ receiving $C C P$

At the time of CCP transfusion, 7 patients were on supplemental oxygen via low flow nasal cannula while 2 patients were on high flow nasal cannula. A marked improvement in oxygen requirement was observed after CCP transfusion in the patients. Seven patients showed rapid weaning to room air within 24 hours and 1 patient within 48 hours. Finally, 1 patient on high flow nasal cannula was weaned to low flow nasal cannula after 48 hours of CCP transfusion and to room air after day 6 . None of the patients required invasive ventilatory support or extracorporeal membrane oxygenation (ECMO). 


\section{Clinical and laboratory findings}

Various clinical and laboratory findings before and 3 days after giving convalescent plasma infusion to the patients were compared and analyzed (Table 2). On day 3 post-CCP, there was a significant increase in oxygen saturation $(\mathrm{p}=0.032)$ while a significant decrease in the respiratory rate from baseline $(p=0.041)$. In addition, there was a significant improvement in the lymphocyte counts ( $p=0.043$ ). However, no significant change in the neutrophil counts, CRP, D-dimer, and LDH was observed.

All the patients showed no signs of complications and were discharged home. The median length of stay in the hospital for these patients was 10 days (range 6-14 days). The median time between CCP administration and discharge was 6 days (range 3-9 days).

Table 2: Clinical and laboratory findings before and after CCP

\begin{tabular}{|c|c|c|c|}
\hline & Before CCP (baseline) & Day 1 post-CCP & Day 3 post-CCP \\
\hline \multicolumn{4}{|l|}{ Clinical findings } \\
\hline Oxygen saturation $(\%)$ & $92(89-95)$ & $97(95-100)$ & $97(96-98)^{*}$ \\
\hline Respiratory rate per minute & $30(24-30)$ & $24(22-30)$ & $22(22-26)^{*}$ \\
\hline \multicolumn{4}{|l|}{ Laboratory findings } \\
\hline Lymphocytes $\times 10^{9} / \mathrm{L}$ (normal range 1.1-3.2) & $0.9(0.3-1.3)$ & $1.2(0.71-2.7)$ & $1.8(1-2.5)^{*}$ \\
\hline Neutrophils x $10^{9} / \mathrm{L}$ (normal range $1.8-6$ ) & $4.1(3.2-4.1)$ & $6.7(3.1-15.8)$ & $5.1(3.7-11.1)$ \\
\hline $\mathrm{CRP}, \mathrm{mg} / \mathrm{L}$ (normal value $<8$ ) & $7.4(1.8-10.8)$ & $3.6(1.1-7.9)$ & $1.5(1-55.7)$ \\
\hline D-dimer & $407(230-1762)$ & $379(226-1467)$ & $889(185-1287)$ \\
\hline LDH & $251(138-317)$ & $222(168-331)$ & $275(103-339)$ \\
\hline
\end{tabular}

\section{(II) Neonatal outcomes}

All the women $(\mathrm{N}=9)$ gave birth to healthy newborns. The median duration from CCP administration to giving birth was 7 weeks (range 0-23 weeks). Only 2 newborns needed admission to the neonatal unit due to either hyperbilirubinemia secondary to blood group incompatibility $(n=1)$ or low birth weight and late prematurity care $(n=1)$. All the neonates had a negative SARSCoV-2 PCR test at 48 hours of age. The neonatal outcomes have been provided in Table 3 .

Table 3: Neonatal Outcomes

\begin{tabular}{|l|l|l|l|l|l|l|}
\hline Patient & $\begin{array}{l}\text { Gestational age at } \\
\text { the time of birth }\end{array}$ & $\begin{array}{l}\text { Type of delivery } \\
\text { method }\end{array}$ & $\begin{array}{l}\text { Birth weight } \\
\text { (grams) }\end{array}$ & $\begin{array}{l}\text { Apgar score } \\
\text { (5-minutes) }\end{array}$ & $\begin{array}{l}\text { Neonatal COVID- } \\
\text { 19 PCR (48 hrs) }\end{array}$ & Neonatal hospitalization \\
\hline 1 & $39^{+4}$ weeks & Vaginal & 3250 & 8 & Negative & No \\
\hline 2 & $37^{+3}$ weeks & Cesarean section & 2940 & 9 & Negative & No \\
\hline 3 & $37^{+5}$ weeks & Vaginal & 2750 & 9 & Negative & $\begin{array}{l}\text { Yes-Hyperbilirubinemia } \\
\text { (blood group incompatibility) }\end{array}$ \\
\hline 4 & 38 weeks & Cesarean section & 3120 & 9 & Negative & No \\
\hline 5 & $33^{+4}$ weeks & Vaginal & 1900 & 8 & Negative & $\begin{array}{l}\text { Yes- Low birth weight and } \\
\text { late prematurity care }\end{array}$ \\
\hline 6 & 39 weeks & Vaginal & 3050 & 10 & Negative & No \\
\hline 7 & $39^{+2}$ weeks & Cesarean section & 2980 & 9 & Negative & No \\
\hline 8 & 37 weeks & Cesarean section & 2750 & 9 & Negative & No \\
\hline 9 & $38^{+3}$ weeks & Vaginal & 3100 & 9 & Negative & No \\
\hline
\end{tabular}

\section{Discussion}

Pregnant women are more prone to severe infections, including COVID-19 and related complications. This may be attributable to the changes in maternal physical stature and the natural proinflammatory immune response, especially during the third trimester of pregnancy [26,27]. Besides, increased oxygen consumption, decreased functional residual capacity, high basal metabolic rate, an elevated diaphragm, airway edema, and hypercoagulable state during the respiratory diseases, including the present COVID-19, may worsen the clinical state of a pregnant woman ${ }^{[28,29]}$. Pneumonia, a significant complication of COVID-19 infection, has also been observed as a remarkable contributing factor to mortality and morbidity in pregnancy ${ }^{[10]}$.

However, as a result of limited evidence on investigating the effects of COVID-19 in pregnant patients and on the babies born to infected mothers, the clinical course or manifestation of COVID-19 is highly unpredictable ${ }^{[30]}$. Vertical transmission of the
SARS-CoV-2 infection through the placenta rarely occurs, as suggested by the published data ${ }^{[31-33]}$. In contrast, a systematic review identified 41 neonates with possible COVID-19 infection but with an overall survival rate of $99 \%$. A case study on 9 women infected with COVID-19 during the third trimester of pregnancy demonstrated an improvement in the clinical course during hospitalization with no complications ${ }^{[31]}$. On the contrary, another study showed pregnancy complications such as fetal distress, premature rupture of the membrane, or stillbirth in 10 out of a total of 13 pregnant patientsx ( 11 patients in the third trimester and 2 in less than 28 weeks of gestation) with SARS-CoV-2 infection. Six patients $(46 \%)$ between 32-36 weeks of gestation had preterm labor. The condition of 1 patient got deteriorated due to multiple organ dysfunction syndromes (MODS), thereby requiring transfer to ICU on intubation and mechanical ventilation. The investigators of the study suggested that it could be the result of the release of a cascade of pro-inflammatory cytokines, also called the 'cytokine storm', in response to the viral load due to COVID-19 infection in these patients ${ }^{[34]}$. 
Additionally, a significant proportion of women ( 10\%) with COVID-19 infection in pregnancy require respiratory support during pandemic, there hospitalization ${ }^{[35,36]}$. Since this number is expected to augment with the spread of the is an urgent need to provide early diagnosis of COVID-19 and appropriate therapeutic management to pregnant women. This would help prevent the mother's condition from worsening, avoid a possible premature delivery or cesarean section, and reduce any potential issues requiring critical care or respiratory support and probable maternal and fetal risk.

For the management of COVID-19, the WHO mainly focuses on preventing infection, providing early detection, monitoring the disease, optimal supportive care, and recommending non-specific treatment against SARS-CoV-2 available to-date (WHO.int). Two monoclonal antibody treatments, bamlanivimaband etesevimab (to be administered in combination), have received emergency use authorization for non-hospitalized COVID-19 patients with mild-moderate symptoms ${ }^{[37]}$. Dexamethasone and other corticosteroids recommended by NIH showed benefit in severe COVID-19 patients hospitalized on ventilator support ${ }^{[38]}$. Based on the findings of the Solidarity Trial, it is suggested that the drugs remdesivir, hydroxychloroquine, lopinavir/ritonavir, and interferon show almost no reduction in the 28-day mortality rate or any improvement in the clinical course of COVID-19 hospitalized patients ${ }^{[39]}$. Besides, encouraging data regarding the safety of convalescent plasma therapy and its use in preventing disease in high-risk cases (with comorbidities, front-line workers including health care providers, and people exposed to confirmed cases) of COVID-19 are rapidly growing. A single dose of CCP resulted in positive clinical and radiological outcomes after 3 and 7 days of the administration, respectively in 10 adults with severe COVID-19 ${ }^{[40]}$. The studies by Hartman et al. (2020), Liu et al. (2020), and Salazar et al. (2020) have demonstrated a greater clinical benefit of early CCP administration than that of delayed immunization in severe COVID-19 patients ${ }^{[34,41,42]}$.

CCP transfusion is based on first collecting large pools of blood plasma from several donors or individuals who were successful in completely recovering from COVID-19 infection. Then, this plasma containing disease-specific antibodies, developed by the individuals' immune system, is infused into the COVID-19 patient to combat the infection ${ }^{[43]}$. Pregnancy is not considered a contraindication to blood plasma transfusion. In the absence of definitive therapy for COVID-19, CCP may prove useful in pregnant patients infected with SARS-CoV-2 because of several reasons: It provides short-term immunity against the disease as the antibodies produced help in neutralizing the virus through complement activation via classical pathway, cellular toxicity, and agglutination; Immunoglobulin G (IgG) passes through the placenta, thus providing the fetus with passive immunity; It has immune-modulatory and anti-inflammatory properties that can suppress the exaggerated production of cytokines, responsible for acute respiratory disease syndrome (ARDS) or multiple-organ failure. Other advantages of using CCP for a novel disease viz. COVID-19 includes its easy availability, lower cost of production, and antibody specificity against the virus.

In view of the safety concerns for both mother and baby, only a few studies have reported the use of different experimental treatments, including CCP therapy in pregnancy ${ }^{[44-46]}$. The results of several ongoing clinical trials reporting the inclusion of pregnant or breastfeeding women infected with COVID-19 are, however, highly awaited to confirm the safety and efficacy of CCP therapy in this patient population.
We, therefore, undertook the present study with an objective to investigate the clinical course, maternal and neonatal outcomes in those pregnant women $(n=9)$ who received CCP therapy for moderate-to-severe COVID-19 infection (per the WHO classification).The most typical presenting symptoms of these patients enrolled in our study were fever, cough, and shortness of breath. The median gestational age of the patients was 31 weeks. All the patients received 2 doses (within 24 hours) of CCP on the median day 5; from the date of a confirmed diagnosis of COVID19. None of them received any antiviral treatment or hydroxychloroquine. After the CCP transfusion, a marked improvement was observed in oxygen requirement in these patients. Seven of them gradually weaned from supplemental oxygen (via high-flow/low-flow cannula) to normal room air within $24 \mathrm{hrs}$. While treating pregnant patients clinically, doctors usually aim at maintaining the oxygen saturation levels at a minimum of $95 \%$. Conforming to this, in our study, the oxygen saturation levels were significantly increased to $97 \%$, and the respiratory rate was significantly decreased on day 3 after the CCP treatment. The lymphocyte count was also significantly increased to $1.8 \times 10^{9} / \mathrm{L}$. The median duration from CCP administration to giving birth was 7 weeks, and all the babies were born healthy with a mean 5-min Apgar score of 8.88. Only 2 neonates required hospitalization in the neonatal unit either because of blood group incompatibility $(n=1)$ or premature low birth weight $(n=1)$. None of the mothers or their newborn babies showed any signs of complications, and they were discharged from the hospital between 3-9 days of CCP administration. All the newborns had negative SARS-CoV-2 PCR test results on days 2 and 5 of age.

Our findings are consistent with the other few published reports available currently. In another similar case study, administration of CCP without antiviral drugs in a pregnant COVID-19 patient at about 24 weeks of gestation depicted a promising clinical outcome for both mother and newborn. Another case of a 26-year old pregnant woman infected with COVID-19 pneumonia gave birth to healthy twins (with no COVID-19 symptoms and negative PCR test) at 36 weeks after given a combination of favipiravir and CCP treatment. Successful management of maternal and perinatal clinical course was reported after using prone positioning and hyperimmune plasma therapy in a case of a 27.4 weeks pregnant severe COVID-19 patient ${ }^{[47]}$. Three other case reports showed the beneficial use of convalescent plasma therapy when combined with antiviral drugs (remdesivir, lopinavir/ritonavir) at a very early gestational age in critically ill obstetric patients.

However, our case series has several limitations. In addition to the small sample size, there is an absence of a control cohort to reach any conclusive benefits with convalescent plasma treatment in COVID-19 in pregnancy. Moreover, the neutralizing antibodies in CCP were not measured. Multiple confounders that could contribute to the changes in the clinical and laboratory findings of the study were also not investigated.

\section{Conclusion}

Our findings demonstrated that CCP therapy is safe and may lead to improved clinical consequences in COVID-19 pregnant patients. Despite the initial positive results regarding the safety and efficacy of CCP treatment, further investigations with a larger sample size are required to make a clear recommendation regarding the routine use of CCP in pregnant women with moderate and severe COVID19. Multidisciplinary management of critically ill COVID-19 pregnant patients and relevant combination therapies are essential 
to warrant the most appropriate maternal and fetal care. Possible side effects or adverse reactions of CCP therapy in patients should be considered well.

\section{Declarations}

Ethics approval and consent to participate: The Ethics Committee of the Ministry of Health of Kuwait (2020/1417\&1420) approved the present study (and is registered at Clinicaltrials.gov NCT04474340).

\section{Consent for Publication}

Not Applicable

\section{Availability of data and Materials}

The data used to support the findings of this study are available from the corresponding author upon request.

\section{Conflict of interest}

None

\section{Funding/Support}

None

\section{Author Contribution}

MA conceptualized and planned the study design, planned data collection, oversaw data collection with FA, literature review, performed the text mining analysis, drafted and revised the final version of the manuscript. MA also performed the statistical analysis. AA and SA conducted the literature review, contributed to the writing and reviewing of the manuscript. All other coauthors contributed to data collection and oversaw the manuscript.

\section{Acknowledgement}

None

\section{References}

[1] World Health Organization. Coronavirus disease (COVID-19) pandemic. Available from: https://www.who.int/emergencies/diseases/novelcoronavirus-2019 Accessed 3 March, 2021).

[2] Wells HL, Letko M, Lasso G, et al. The evolutionary history of ACE2 usage within the coronavirus subgenus Sarbecovirus. Virus Evolution 2021. https://doi.org/10.1101/2020.07.07.190546

[3] World Health Organization. Geneva (Switzerland): World Health Organization, 2020. WHO DirectorGeneral's remarks at the media briefing on 2019-nCoV on 11 February 2020. Available from: https://www.who.int/dg/speeches/detail/who-directorgeneral-s-remarks-at-the-media-briefing-on-2019-ncovon-11-february-2020

[4] World Health Organization. Women of reproductive age (15-49 years) population (thousands). Available from: https://www.who.int/data/maternal-newbornchildadolescent/indicator-explorer-new/mca/women-of- reproductive-age-(15-49 years)_ population-(thousands) Accessed 20 April 2020.

[5] Dashraath P, Wong JL, Lim MX, et al. Coronavirus disease 2019 (COVID-19) pandemic and pregnancy. Am $J \quad$ Obstet Gynecol 2020; 222: 521-31. https://doi.org/10.1016/j.ajog.2020.03.021

[6] Pierce-Williams RA, Burd J, Felder L, et al. Clinical course of severe and critical coronavirus disease 2019 in hospitalized pregnancies: a United States cohort study. Am J Obstet Gynecol MFM 2020; 2: 100134. https://doi.org/10.1016/j.ajogmf.2020.100134

[7] CDC. Data on COVID-19 during Pregnancy | CDC 2020. Available from: https:// www.cdc.gov/coronavirus/2019ncov/cases-updates/special-populations/pregnancy-dataon-covid-19.html Accessed July 21, 2020.

[8] Allotey J, Stallings E, Bonet M, et al. Clinical manifestations, risk factors, and maternal and perinatal outcomes of coronavirus disease 2019 in pregnancy: living systematic review and meta-analysis. BMJ 2020; 370: m3320. https://doi.org/10.1136/bmj.m3320

[9] Novoa RH, Quintana W, Llancarí P, Urbina-Quispe K, Guevara-Ríos E, Ventura W. Maternal clinical characteristics and perinatal outcomes among pregnant women with coronavirus disease 2019. A systematic review. Travel Med Infect Dis 2020; 39: 101919. https://doi.org/10.1016/j.tmaid.2020.101919

[10] Stumpfe FM, Titzmann A, Schneider MO, et al. SARSCoV-2 Infection in Pregnancy - a Review of the Current Literature and Possible Impact on Maternal and Neonatal Outcome. Geburtshilfe Frauenheilkd 2020; 80: 380-90. https://doi.org/10.1055/a-1134-5951

[11] CDC COVID-19 Response Team. Preliminary estimates of the prevalence of selected underlying health conditions among patients with Coronavirus Disease 2019-United States, February 12-March 28, 2020. MMWR Morb Mortal Wkly Rep 2020; 69: 382-6. https://doi.org/10.15585/mmwr.mm6913e2

[12] Di Mascio D, Khalil A, Saccone G, et al. Outcome of coronavirus spectrum infections (SARS, MERS, COVID-19) during pregnancy: a systematic review and meta-analysis. Am J Obstet Gynecol MFM 2020; 2: 100107. https://doi.org/10.1016/j.ajogmf.2020.100107

[13] Yang Z, Wang M, Zhu Z, Liu Y. Coronavirus disease 2019 (COVID-19) and pregnancy: a systematic review. $J$ Matern Fetal Neonatal Med 2020; 30: 1-4. https://doi.org/10.1080/14767058.2020.1759541

[14] Wang X, Guo X, Xin Q, et al. Neutralizing antibodies responses to SARS-CoV-2 in COVID-19 inpatients and convalescent patients. Clin Infect Dis 2020; ciaa721. https://doi.org/10.1101/2020.04.15.20065623

[15] Casadevall A, Pirofski LA. The convalescent sera option for containing COVID-19. J Clin Invest 2020; 130: 1545-48. https://doi.org/10.1172/jci138003

[16] Cheng Y, Wong R, Soo YO, et al. Use of convalescent plasma therapy in SARS patients in Hong Kong. Eur $J$ Clin Microbiol Infect Dis 2005; 24: 44-6. https://doi.org/10.1007/s10096-004-1271-9

[17] Luke TC, Kilbane EM, Jackson JL, Hoffman SL. Metaanalysis: convalescent blood products for Spanish influenza pneumonia: a future $\mathrm{H} 5 \mathrm{~N} 1$ treatment? Ann Intern $\quad$ Med 2006; 145: 599-609. https://doi.org/10.7326/0003-4819-145-8-20061017000139 
[18] Sarkar S, Soni KD, Khanna P. Convalescent plasma is a clutch at straws in COVID-19 management! A systematic review and meta-analysis. J Med Virol 2021; 93: 1111-18. https://doi.org/10.1002/jmv.26408

[19] Tanne JH. Covid-19: FDA approves use of convalescent plasma to treat critically ill patients. BMJ 2020; 368: m1256. https://doi.org/10.1136/bmj.m1256

[20] Anderson J, Schauer J, Bryant S, Graves CR. The use of convalescent plasma therapy and remdesivir in the successful management of a critically ill obstetric patient with novel coronavirus 2019 infection: a case report. Case Rep Womens Health 2020; 27: e00221. https://doi.org/10.1016/j.crwh.2020.e00221

[21] Grisolia G, Franchini M, Glingani C, et al. Convalescent plasma for coronavirus disease 2019 in pregnancy: a case report and review. Am J Obstet Gynecol MFM 2020; 2: 100174. https://doi.org/10.1016/j.ajogmf.2020.100174

[22] Jafari R, Jonaidi-Jafari N, Dehghanpoor F, Saburi A. Convalescent plasma therapy in a pregnant COVID-19 patient with a dramatic clinical and imaging response: a case report. World J Radiol 2020; 12: 137-41. https://doi.org/10.4329/wjr.v12.i7.137

[23] Pastick KA, Nicol MR, Smyth E, et al. A Systematic Review of Treatment and Outcomes of Pregnant Women With COVID-19-A Call for Clinical Trials. Open Forum Infect Dis 2020; 7(9). https://doi.org/10.1093/ofid/ofaa350

[24] Alsharidah S, Ayed M, Ameen RM, et al. COVID-19 convalescent plasma treatment of moderate and severe cases of SARS-CoV-2 infection: A multicenter interventional study. Int J Infect Dis 2021; 103: 439-46. https://doi.org/10.1016/j.ijid.2020.11.198

[25] Integrated Management of Adolescent and Adult Illness (IMAI) District Clinician Manual: Hospital Care for Adolescents and Adults. Guidelines for the management of common illnesses with limited resources. Geneva, Switzerland: World Health Organization; 2011.

[26] Liu H, Wang LL, Zhao SJ, Kwak-Kim J, Mor G, Liao AH. Why are pregnant women susceptible to COVID19? An immunological viewpoint. J Reprod Immunol 2020; 139: 103122. https://doi.org/10.1016/j.jri.2020.103122

[27] Abbas AM, Fawzy AT, Fathy SK. Use of Convalescent Plasma for COVID-19 in Pregnancy: Lessons from other Viruses. Am J Biomed Sci Res 2020; 9: 427-33. https://doi.org/10.34297/ajbsr.2020.09.001443

[28] Louie JK, Acosta M, Jamieson DJ, Honein MA. Severe 2009 H1N1 influenza in pregnant and postpartum women in California. N Engl J Med 2010; 362: 27-35. https://doi.org/10.1056/nejmoa0910444

[29] Vlachodimitropoulou Koumoutsea E, Vivanti AJ, Shehata N, et al. COVID-19 and acute coagulopathy in pregnancy. J Thromb Haemost 2020; 18: 1648-52. https://doi.org/10.1111/jth.14856

[30] Zaigham M, Andersson O. Maternal and perinatal outcomes with COVID-19: A systematic review of 108 pregnancies. Acta Obstet Gynecol Scand 2020; 99: 8239. https://doi.org/10.1111/aogs.13867

[31] Chen H, Guo J, Wang C. Clinical characteristics and intrauterine vertical transmission potential of COVID-19 infection in nine pregnant women: a retrospective review of medical records. Lancet 2020; 395: 809-15. https://doi.org/10.1016/s0140-6736(20)30360-3
[32] Liu ST, Lin HM, Baine I, et al. Convalescent plasma treatment of severe COVID-19: a matched control study. medRxiv 2020; 26: 1708-13. https://doi.org/10.1038/s41591-020-1088-9

[33] Mimouni F, Lakshminrusimha S, Pearlman SA, Raju T, Gallagher PG, Mendlovic J. Perinatal aspects on the covid-19 pandemic: a practical resource for perinatalneonatal specialists. J Perinatol 2020; 40: 820-26. https://doi.org/10.1038/s41372-020-0665-6

[34] Liu Y, Chen H, Tang K, Guo Y. Clinical manifestations and outcome of SARS-CoV-2 infection during pregnancy. J Infect 2020 (Online ahead of print). https://doi: 10.1016/j.jinf.2020.02.028

[35] Center for Disease Control and Prevention. Data on COVID-19 during pregnancy. Available from: https://www.cdc.gov/coronavirus/2019-ncov/casesupdates/special-populations/pregnancy-data-on-covid$\underline{19 . h t m l}$

[36] Knight M, Bunch K, Vousden N, et al. Characteristics and outcomes of pregnant women admitted to hospital with confirmed SARS-CoV-2 infection in UK: national population based cohort study. BMJ 2020; 369: m2107. https://doi.org/10.1136/bmj.m2107

[37] Coronavirus (COVID-19) Update: FDA Authorizes Monoclonal Antibodies for Treatment of COVID-19 | FDA. Available from: https://www.fda.gov/newsevents/press-announcements/coronavirus-covid-19update-fda-authorizes-monoclonal-antibodies-treatmentcovid-19-0

[38] RECOVERY Collaborative Group: Horby P, Lim WS, Emberson JR, et al. Dexamethasone in Hospitalized Patients with Covid-19. N Engl J Med 2021; 384: 693704. https://doi.org/10.1056/nejmoa2021436

[39] WHO Solidarity trial consortium (15 October 2020). Repurposed antiviral drugs for COVID-19-interim WHO SOLIDARITY trial results (PDF). MedRxiv doi:10.1101/2020.10.15.20209817. S2CID 222373329

[40] Duan K, Liu B, Li C, et al. Effectiveness of convalescent plasma therapy in severe COVID-19 patients. Proc Natl Acad Sci USA 2020; 117: 9490-6.

[41] Hartman W, Hess AS, Connor JP. Hospitalized COVID19 patients treated with Convalescent Plasma in a midsize city in the Midwest. medRxiv 2020. https://doi.org/10.21203/rs.3.rs-54167/v2

[42] Salazara E, Christensena PA, Gravissa EA, et al. Treatment of COVID-19 Patients with Convalescent Plasma Reveals a Signal of Significantly Decreased Mortality. Am J Pathol 2020; S0002-9440.

[43] Burnouf T, Seghatchian J. Ebola virus convalescent blood products: where we are now and where we may need to go. Transfus Apher Sci 2014; 51: 120-25. https://doi.org/10.1016/j.transci.2014.10.003

[44] Zhang B, Liu S, Tan $\mathrm{T}$, et al. Treatment with convalescent plasma for critically ill patients with severe acute respiratory syndrome coronavirus 2 infection. Chest 2020; 158: e9-13. https://doi.org/10.1016/j.chest.2020.03.039

[45] Magallanes-Garza GI, Valdez-Alatorre C, DávilaGonzález D, Martínez-Reséndez MF, Sánchez-Salazar SS, Castilleja-Leal F, et al. Rapid improvement of a critically ill obstetric patient with SARS-CoV-2 infection after administration of convalescent plasma. Int $J$ 
Gynaecol Obstet 2020. [Epub ahead of print]. https://doi: 10.1002/ijgo. 13467

[46] Soleimani Z, Soleimani A. ADRS due to COVID-19 in midterm pregnancy: successful management with plasma transfusion and corticosteroids. J Matern Fetal Neonatal Med 2020. [Epub ahead of print]. https://doi: 10.1080/14767058.2020.1797669

[47] Donzelli M, Ippolito M, Catalisano G, Renda B, Tarantino F, Diquattro O, et al. Prone positioning and convalescent plasma therapy in a critically ill pregnant woman with COVID-19. Clin Case Rep 2020; 8: $3352-$ 58. https://doi.org/10.1002/ccr3.3426
Open Access This article is licensed under a

Creative Commons Attribution 4.0 International License, which permits use, sharing, adaptation, distribution and reproduction in any medium or format, as long as you give appropriate credit to the original author(s) and the source, provide a link to the Creative Commons license, and indicate if changes were made. The images or other third party material in this article are included in the article's Creative Commons license, unless indicated otherwise in a credit line to the material. If material is not included in the article's Creative Commons license and your intended use is not permitted by statutory regulation or exceeds the permitted use, you will need to obtain permission directly from the copyright holder. To view a copy of this license, visit https://creativecommons.org/licenses/by/4.0/.

(C) The Author(s) 2021 